\title{
I I
}

\section{Tres aspectos do decreto de re- ajustamento economico}

\author{
Waldemar Ferreira
}

Os direitos do credor hipotecário arrematante dos bens, pelo saldo de seu crédito, em face do decreto do reajustamento econômico

O credor de Rs. 260:000\$000 moveu contra o devedor o executivo hipotecario. A garantia era um imovel cafeeiro. Arrematou-o, em praça, em benefício do seu crédito, por 150:000\$000. Não extraiu, todavia, a necessaria carta de arrematação. Mas deu, como não podia deixar de ter acontecido, quitação da importancia do preço da arrematação.

Pergunta-se :

Pelo fato de se não haver dado baixa do onus hipotecario, no registro competente, mediante averbação feita pelo respectivo serventuário; e pelo fato de não constar o registro dessa carta de arrematação dos bens hipotecados - estará o débito todo, ou em parte, abrangido pelo decreto do reajustamento econômico (decr. n. 23.533, de 1 de dezembro de 1933)? 


\section{PARECER}

Não. Sem embargo de se não haver dado baixa ao onus hipotecario, no registro competente, e de se não ter operado a transcrição, pelo registro da carta de arrematação, dos bens hipotecados para o nome do arrematante - a dívida, de que se trata, não ficou reduzida de cincoenta por cento, nos termos do decr. n. 23.533, de 1 de dezembro de 1933:

a) no todo, porque, então, já se encontrava ela reduzida na sua importancia. Era ela, em 1932, de

Rs. 260:000\$000. Promovido o executivo hipotecario, seguiu o processo os seus termos regulares e, ao fim dele, arrematados os bens hipotecados, penhorados e praceados, reduziuse a dívida á importância de Rs. 150:200\$000. Arrematouos o proprio credor, em benefício do seu crédito. Imputou-se o preço da arrematação no pagamento, dando-se quitação dele. Além de tudo, tanto em razão disso, quanto por ef eito da arrematação, ficou o crédito destituido de garantia.

Quando - eis a regra consignada no art. 767 do codigo civil - excutido o penhor, ou executada a hipoteca, o produto não bastar para o pagamento da divida e despesas judiciais, continuará o devedor obrigado, pessoalmente, pelo resto.

A divida, que era privilegiada, em quirografária se converteu. Esgotada a garantia real, pessoal veiu a ser a responsabilidade do devedor. Não ficou êste, conseqüentemente, embora agricultor fosse ou tivesse sido, no momento da publicação do decreto, de reajustamento econômico chamado, no gozo do benefício por êle instituido, por não estar o seu debito garantido com hipoteca ou penhor.

A circunstancia de não ter sido dado baixa, no registro imobiliario, á inscrição hipotecaria, não importava na subsistencia do crédito já amortizado pela arrematação. Nem seria lícito ao devedor, como ao credor, prevalecer-se disso para, fingindo ignorar o pagamento feito, dar a divida como existente e realmente garantida em sua totalidade. 
Reduzida estava ela pela arrematação; e, pela arrematação, desprovida da garantia hipotecaria.

b) em parte, porque, não sendo o credor um banco, nem casa bancária, inaplicavel era, ao tempo da publicação do decreto, ao saldo quirografario, o disposto no seu art. 2, nestes termos concebido:

"Fica igualmente reduzido de cincoenta por cento o valor do débito dos agricultores, qualquer que seja a sua natureza, a bancos e casas bancárias, desde que contraidos antes de 30 de junho do corrente ano, no caso de ser de insolvencia o estado do devedor".

Não sendo garantido com hipoteca ou penhor a divida dos agricultores para com bancos e casas bancárias, sómente ficou reduzida de cincoenta por cento a cujo devedor se encontrava, na data da publicação do decreto, em estado de insolvencia. Exprime-se esta por varios índices exteriores. Incerta e vária tem sido a jurisprudencia de todos os paises no conceitua-la. De haver o art. 1.554 do codigo civil determinado proceder-se ao concurso de credores, toda vez que as dívidas excedam á importancia dos bens do devedor, escreveu Clovis Bevilaqua, Codigo Civil Comentado, vol. 5, pag. 339, que "o estado de insolvencia aparece na execução promovida por algum credor, porque, então, se manifesta a insuficiencia do ativo para cobrir o passivo do devedor; mas poderá ser provado por outros modos, como, por exemplo, no caso de alienação fraudulenta, por documentos ou testemunhas"

Fala-se na proxima expedição de um regulamento do decreto do reajustamento economico. (1) Nele, sem dúvi-

(1) Expediu-se, em verdade, o regulamento, no intuito de esclarecer, modificar e completar alguns dispositivos do decr. $n$. 23.523, de 1 de dezembro de 1933, de modo a acentuar o seu caráter de proteção aos agricultores.

Foi êle aprovado pelo decr. n. 23.981, de 9 de março de 1934, cujo art. 6, d) acentuou caber a indenização de cincoenta por cento, de que trata o art. 3 do decr. n. 23.523, a todo credor de agricultor, por divida existente a 1 de dezembro de 1933, mas ante- 
da, se esclarecerá êste ponto, de tanta relevancia. Dir-se-á, por certo, como se fará a prova do estado de insolvencia para a invocação do beneficio prodigalizado.

São Paulo, 11 de janeiro de 1934

rior a 30 de junho daquele ano, desde que êle se obrigue "a dar quitação plena de toda a divida, nos casos em que, sendo o valor da garantia inferior á metade do da dívida, seja tambem de insolvencia a situação do devedor".

Os bens que, por êsse motivo, se liberarem, não responderão por dividas anteriores á quitação.

Tambem os bancos e casas bancarias, na mesma situação, terão de dar quitação plena ao devedor insolvente, por ocasião do recebimento das apólices.

Não estabeleceu o decr. n. 23.523 o processo para a unificação da insolvencia. Nem o decr. n. 24.233, de 12 de maio de 1934, consolidador dos dispositivos anteriores. Decorrerá ela, sem duvida, da comparação entre o vialor das dividas, que deverão ser minudentemente mencionadas, e o dos bens do devedor. $O$ valor destes não será o estipulado no contrato, mas o efetivo valor atual, verificado pela fórma que a camara determinar, mesmo quando devedor e credor acordarem na quitação plena. Atribuiu, no entanto, á Camara de Reajustamento Economico a faculdade de servir-se de todos os meios de verificação da legitimidade e exatidão das declarações de credito comunicadas ou requeridas, inclusivé exame de escrituração. Declarou o regimento interno daquela Camara, ademais, ser seu representante o Banco do Brasil, para o efeito de, por prepostos seus, fazer todas as diligencias, exames e verificações das declarações de credito, inclusivé de escrituração de bancos, casas bancarias e comerciantes em geral, podendo, para esse fim, recorrer ao auxilio da Fiscalização Bancaria e de quaisquer repartições publicas, assim como de autoridades judiciarias e administrativas, notarios, tabeliães, escrivães e outros serventuarios da Justiça e oficiais de quaisquer registros publicos.

Não se conformando qualquer interessado com a avaliação feita pelos prepostos da Camara, tem o direito de pleitear, por escrito, perante a mesma, nova avaliação, uma vez que justifique o seu pedido. 


\section{A qualidade do credor para a invocação dos benefícios do reajustamento}

Certo devedor de quantia tomada a mutuo deu seus prédios urbanos em garantia da dívida em 1932. Naquele mesmo ano arrematou em praça um imovel agricola cafeeiro. Arrematou-o mas não fez extrair a respectiva carta de arrematação. Deixou, porisso, de fazer a devida transcrição no registro imobiliario. Entrou, todavia, na posse do imovel arrematado e vem pagando os impostos que sôbre êle recaem, colhendo e vendendo os seus frutos por sua conta, como seus. Praticou, desde então, a profissão de agricultor, como se seu titulo aquisitivo tivesse sido passado e revestido de todos os requisitos legais.

\section{Pergunta-se:}

De acôrdo com os arts. 1 e 2 e paragr. 2 dêste artigo do decreto do reajustamento economico, o de n. 23.533, de 1 de dezembro de 1933, está o seu debito hipotecário, com garantia de prédios urbanos, sujeito aos efeitos dêsse decreto, e reduzido, porisso, á metade?

\section{PARECER}

Tem a arrematação de bens levados a praça, com a inteira observancia das essenciais solenidades desta, efei- 
tos especificos. Comprovar-se-á pelo auto de arrematação (art. 1.034 do codigo do processo), assinado pelo juiz, porteiro e arrematante, finda a praça. Tanto quanto a adjudicação, reputa-se perfeita com a assinatura daquele auto, independentemente de sentença. Não é esta de mister para a decorrencia dos seus efeitos, porque ela se realiza e funciona como venda, sem embargo do seu feitio judicial, a quem tiver oferecido o maior preço, a quem mais deu. Por isso, e ficou expresso no art. 1.035 do aludido codigo processual, não se desfará a arrematação, senão nos seguintes casos:

a) de ser anulada;

b) de não ser pago o preço ou prestada a fiança;

c) de verificar-se a hipótese do art. 855 do código civil, isto é, de, tocando preferencia á Fazenda Federal ou Estadual não se ter feito a uma ou outra a intimação para, dentro de quinze dias, utiliza-la, se quiser, pagando o preço da arrematação;

d) de provar o arrematante, nos tres dias seguintes, a existencia de onus reais não mencionados no edital de praça.

Lavrado o auto de arrematação e assinado êle pelo juiz, porteiro e arrematante e seus fiadores, quando houver, prelecionou Joño Monteiro, Programma do Curso de Processo Civil, vol. 3, paragr. 273, pag. 303, a arrematação se consuma com a expedição da respectiva carta e a imissão do arrematante na posse do objeto arrematado. Tem sido muito debatida a questão de saber desde quando, nas arrematações judiciais, se opera a transferencia do dominio. Pondo a controvérsia no tapete da discussão, aquele eminente processualista assim a resolveu: "para uns, do momento da arrematação; para outros, desde o pagamento ou consignação do preço; ainda para outros, da entrega da carta de arrematação; finalmente, para quarta escola, da imissão na posse da cousa arrematada, mediante a carta de arrematação. E' esta a nossa opinião"

Pelo sistema do código civil, expresso no art. 530, n. I, 
entretanto, adquire-se a propriedade imovel "pela transcrição do titulo de transferencia no registro do imovel" Não paira a mínima dúvida a respeito. Não se pode invocar o direito de propriedade senão fundado em titulo regularmente transcrito. No caso, está bem claro na exposição, feita a arrematação não chegou, entretanto, a consumar-se a translação da propriedade imovel pelo não ter sido extraida a respectiva carta de arrematação, por isso mesmo não transcrita.

Não se cogita, todavia, de saber se, efetivamente, o arrematante se tornou proprietario dos bens imoveis, que arrematou. Arrematando-os, e posto não tivesse sido expedida a carta, entrou êle, de fato, realmente, na posse dos arrematados, que eram uma fazenda de plantio e cultura de café. Passou a administra-la como legítimo proprietario e a explora-la agrícolamente, tomando sôbre si a responsabilidade de todos os encargos dessa exploração decorrentes. Pôs-se a trata-la convenientemente, provendo a todas as suas necessidades. Arcou com as despesas do seu custeio. Pagou os impostos sôbre ela lançados. Colheu os seus frutos. Beneficiou-os. Ensacou-os. Transportou-os. Vendeu-os. Agiu, em todos êsses passos, deliberadamente, como quem adotou uma nova profissão. Se antes não o era, desde então se tornou um agricultor, fossem quais fossem as objeções oponiveis á legitimidade do seu direito de propriedade, por ninguem, de resto, contestado. (2)

(2) Esclarecendo quais os beneficiarios da indenisação concedida pelo decreto do reajustamento economico, o decreto n. 23.981, de 9 de março de 1934, que o regulamentou, deixou bem claro, no art. 16, serem "agricultores, para os efeitos dêste decreto, todas as pessoas, fisicas ou juridicas, que exerçam, profissionalmente, por conta propria, e com fins de lucro, a exploração agricola, mesmo a extrativa, a criação ou a invernagem de gado, ainda quando associem a essas atividades o beneficiamento ou transformação industrial dos respectivos produtos"

Excetuados ficaram "os donos de propriedade rural e agricola arrendada a terceiro para quaisquer dos fins mencionados no artigo, e que não exerçam diretamente a agricultura, salvo quando a divida 
Foi isso em fins de 1932.

Publicou-se, um ano depois, o decr. n. 22.533, de 1 de dezembro de 1933, que reduziu de cincoenta por cento o valor, naquela data, dos débitos de agricultores, contraidos antes de 30 de junho daquele ano, que tivessem garantia real ou pignoraticia. De seus dispositivos decorrem serem requistos para a obtenção daquele abatimento de cincoenta por cento:

a) ser o devedor agricultor, considerando tal o art. 2, paragr. 2, afim de gozar da vantagem estabelecida, a pessôa física ou jurídica que exercer a sua atividade na agricultura, criação ou invernagem de gado, embora exerça tambem, outra atividade, ou não;

b) ser a dívida anterior a 30 de junho de 1933, ou, se posterior áquela data, novação de dívida anterior;

c) estar a divida garantida por onus real ou pignoratício. Serviu-se o decreto da expressão "garantia real ou pignoratícia" O penhor é uma garantia real tambem. Empregou, como se percebe logo, a expressão "garantia real" imprópriamente, como querendo referir-se á garantia hipotecaria. (3)

Não teve o decreto para a concessão do benefício, em conta a natureza da dívida ou da sua garantia. Não entrou

ou sua novação se tenha constituido em tempo em que estivessem no exercicio da atividade agricola".

Nos termos do art. 21, $\S 3$, do decr. n. 24.233, de 12 de maio de 1934, o exercicio da profissão agricola deverá ser comprovado mediante apresentação de conhecimentos de impostos relativos á mesma profissão, quando houver, a certidão do registro como agricultor ou, ainda, por atestado autentico dos prefeitos municipais e dos coletores federais ou estaduais.

(3) Conferiu o art. 6 do decr. n. 23.981, de 9 de março de 1934, o direito á indenização de cincoenta por cento a todo o credor de agricultor por divida existente a 1 de dezembro de 1933, com a condição de:

a) ser a divida anterior a 30 de junho de 1933, refórma ou novação desta;

b) ter garantia real; 
na análise de ser a dívida proveniente de encargos assumidos pelo agricultor em razão da sua indústria agrícola. Nem na indagação de ser agrícola ou urbano o prédio dado em hipoteca. (4) Teve em mira beneficiar o agricultor, remediando os males advindos da crise generalizada, que criou

c) ser nela o agricultor devedor e principal pagador ou, se se tratar de cambial, ser emitente ou aceitante do titulo, ou ainda sacador, desde que o saque represente utilização de crédito aberto pelo sacado;

d) obrigar-se o credor a dar plena quitação de toda a divida, nos casos em que, sendo o valor da garantia inferior á metade do da divida, seja, tambem, de insolvencia a situação do devedor.

(4) Excluiu o decr. n. 23.981, art. 10, do seu regime e do decr. n. 23.533:

a) as dividas contraidas em moeda estrangéira, salvo quando ajustadas dentro do país, e nele exigiveis, devendo o valor destas ser calculado pelo cambio da data do contrato;

b) as dividas contraidas por agricultores, quando se verifique do proprio instrumento que se destinaram a fim estranho á atividade agricola;

c) as dividas garantidas exclusivamente por hipoteca de propriedades urbanas, ou penhor mercantil, salvo sendo banco ou casa bancaria o credor e insolvente o devedor;

d) as dividas constituidas expressamente para a aquisição de imoveis, urbanos ou agricolas.

O regulamento, como se vê, alterou e ampliou os dispositivos anteriores, em mais de um passo.

Veiu, depois, o decr. n. 24.233, de 12 de maio de 1934. Consolidou os dispositivos dos decretos anteriores. Excluiu o seu art. 20 do seu regime, além das dividas acima enumerados nas letras a) e $b$ ) mais as seguintes:

c) as dividas cuja garantia exclusiva sejam direitos reais sobre propriedades urbanas, penhor mercantil ou civil, salvo o previsto no art. 12 ;

d) as dividas expressamente constituidas para aquisição de imoveis urbanos ou rurais;

e) as dividas expressamente constituidas dentro dos tres dias seguintes á aquisição do imovel, salvo prova de que a duvida não se destinou á aquisição;

f) as debentures (obrigações ao portador). 
uma situação de graves dificuldades para a quasi totalidade dos agricultores ou seja a propria economia nacional, que na agricultura assenta as suas bases.

Isto posto, respondo:

- Sim. O débito, de que se trata, ficou reduzido de cincoenta por cento, nos termos do decr. n. 23.533, de 1 de dezembro de 1933.

São Paulo, 10 de janeiro de 1934 


\section{III}

\section{0 penhor agrícola em face do decreto do reajustamento econômico}

Feito um emprestimo da importancia de ... 200:000\$000, deu o devedor ao credor penhor agricola de 7.000 sacas de café da safra de 1933 de sua propriedade agricola.

Deveria a divida ser resgatada até 1 de dezembro daquele ano, salvo motivo de fôrça maior, a critério do credor. Estabeleceu-se a multa de 50:000\$000 para o caso de inadimplemento de qualquer clausula ou obrigação contratual, mais $20 \%$ no caso de execução judicial da dívida.

Se o café apenhado não bastasse para o completo pagamento da divida e juros, seria integralizado com o de outras procedencias ou com o pagamento em especie, não podendo haver demora alem de dez dias, sob pena de rescisão do contrato.

Até á data estipulada haviam sido entregues apenas 500 sacas do café apenhado.

Interpelado, entrou o devedor com mais 300 .

Pergunta-se :

I. E' exequivel o contrato pela metade, em face da lei do reajustamento ?

II. Pagar-se-á essa metade dividindo-se a importancia da dívida por dois e abatendo-se o que já foi pago da metade que lhe compete, ou do total devido atualmente ?

III. Pode o devedor, rescindido, como está, o contrato, invocar a faculdade de pagar a divida em dez prestações, ou tem que pagar os $50 \%$ de uma só vez ? 


\section{PARECER}

Só se póde convencionar pelo prazo de um ano, ulteriormente prorrogavel por seis meses, o penhor agricola. Porisso, dando a C \& C, por empréstimo, em 1 de dezembro de 1932, a importancia de Rs. 200:000\$000, convencionou C P dever o seu reembolso efetuar-se em 1 de dezembro de 1933, salvo motivo de fôrça maior, com a entrega de sete mil sacas de café, produção dos cafesais de certa fazenda do devedor, na safra daquele ano, dadas em penhor agricola, como garantia da dívida.

Estava em execução o contrato de penhor agricola, quando o decr. n. 22.626, de 7 de abril de 1933, estabeleceu, no seu art. 10, poderem ser pagas em dez prestações anuais iguais e continuadas, a juizo do devedor, se existentes naquela data:

a) as dividas garantidas com hipoteca rurais ou penhores agricolas (art. 1, paragr. 1, in fine);

b) as obrigações expressas e declaradamente contraidas para financiamento de trabalhos agricolas, ou para compra de maquinismos e de utensilios destinados á agricultura, qualquer que seja a modalidade da dívida, desde que tenham garantia real (art. 1, paragr. 2).

Alargando para dez anos, contados da data de sua publicação, os prazos das dívidas então existentes e nestes dois itens mencionados, o decreto determinou, por outro lado, o pagamento do capital devido em dez prestações anuais iguais e continuadas, devendo efetuar-se o pagamento da primeira prestação decorrido um ano de sua publicação, sob pena de vencimento da dívida e do exercício pelo credor da ação competente para a execução da hipoteca ou para a excussão do penhor agricola.

Tendo, por essa fórma, concedido ao devedor o benefício de uma longa moratoria, não o eximiu o decreto, en- 
tretanto, quando houvesse garantido a sua dívida com penhor agricola de frutos de sua fazenda, das obrigações dêste decorrentes. Se o prazo da dívida, que era, por fôrça de lei expressa, de um ano, prorrogavel por seis meses, passou a ser de dez anos, a garantia pignoraticia ficou sendo, sem dúvida, a mesma. Tendo êle, como na hipótese sujeita a meu exame, dado em penhor agricola sete mil sacas de café de produção dos seus cafezais, estabeleceu-se sôbre essa produção o direito real do contrato resultante para o credor, o jus pignoris, isto é, o direito de sequela e de preferencia. As obrigações do devedor pignoraticio ficaram sendo as mesmas, sem embargo da dilatação do prazo para o pagamento de sua divida. O penhor não sofreu alteração alguma, pela razão, exarada no art. 755 do código civil, de, nas dividas garantidas por penhor, anticrese ou hipoteca, a coisa dada em garantia ficar sujeita, por vínculo real, ao cumprimento da obrigação. $\mathrm{E}$ isso na sua integralidade.

Se, como refere o art. 758 do codigo civil, "o pagamento de uma ou mais prestações da dívida não importa exoneração correspondente da garantia, ainda que esta compreenda varios bens, salvo disposição expressa, no titulo ou na quitação" - bem é de concluir, pelas mesmas razões, tambem não importar naquela exoneração o alargamento do prazo da divida garantida por penhor, hipoteca ou anticrese. Não perca ninguem, quanto a isto, o precioso ensinamento de Cuovis Bevilaqua, no Código Civil Comentado, vol. 3, 3. ${ }^{\text {a }}$ ed., pag. 335 :

"O direito real de garantia é indivisivel. Ainda quando a obrigação e a objeto, sôbre que recái o direito de crédito, sejam divisiveis, o vinculo jurídico da garantia real será indivisivel. Quer isto dizer: I, Que subsiste inteiro sôbre os bens dados em garantia, e sôbre cada uma de suas partes. E' o que LACERDa chama integralidade. II, Que não se fraciona, não se adquire, nem se perde por partes. A integralidade é da essencia do vínculo real de garantia. Quanto acrescer á coisa, se lhe submete. Est totum in toto et in qualibet parte, seja lícito dizer, modificando, ligeiramente, 
a repetida frase de Dumolin. A indivisibilidade, própriamente dita, do vínculo, não é da essencia da relação jurídica; é criação da lei, em benefício do crédito. Porisso as partes podem afasta-la, quer no titulo constitutivo, quer em ato posterior, quando o devedor solve uma parte da divida"

Dificilmente se poderia dizer melhor e com mais autoridade. Não se alterou o direito real de garantia com a ampliação do prazo da divida, dado que o devedor tenha usado do direito, que o decreto deixou ao seu alvitre, de efetuar-lhe o pagamento no prazo de dez anos, em dez prestações anuais iguais e continuadas. Tão pouco o alterou o decr. n. 22.533 , de 1 de dezembro de 1933, cujo primeiro artigo reduziu de cincoenta por cento o valor, naquela data, de todos os debitos de agricultores, contraidos antes de 30 de junho de 1933, quando tiverem garantia real ou pignoratícia. $\mathrm{E}$ não o alterou em razão da indivisibilidade do vínculo juridico da garantia real. Tambem as partes não a modificaram, nem no titulo constitutivo da divida, nem por contrato posterior.

Dilatou-se por dez anos o prazo para o pagamento da dívida? Ficou, posteriormente, reduzida ela, por fôrça de lei, de cincoenta por cento no seu valor?

Pouco importa. A garantia ficou sendo a mesma: o penhor agricola de sete mil sacas de café, da safra de 1933, da fazenda de propriedade do devedor. Não tornou o decreto ditatorial divisivel a garantia real dada pelos agricultores beneficiados tanto pela diminuição, pela metade, de suas dividas, quanto pelo aumento, para dez anos, do prazo para paga-las. Não fez, a êste respeito, a mínima referencia. Todo o penhor dado garante a divida ou parte dela, tenha ela se reduzido por efeito de amortizações parciais, ou, como no caso, por ef eito de disposição legal. Porisso doutrinou o Visconde de Ouro Preto, em Credito Movel pelo Penhor e Bilhete de Mercadorias, pag. 25, n. 22, ser o penhor indivisivel: "grava os bens integralmente e em cada uma de suas partes, em favor da dívida total, ou de fração dela, qualquer que seja a pessoa em cujo poder se achem" 
E concluiu:

"Totam in tota et totam in qualibet parte, tal é o principio. Enquanto não fôr pago do ultimo real está o credor em seu direito guardando a integralidade do penhor: donec ad unum numum solvatur, si valit, retinebit"

Subsistem, por via de conseqüência, as obrigações do devedor, na qualidade de depositario, que ficou sendo, por ef eito da clausula constituti, das sete mil sacas de café, em que foi estimada a produção dos seus cafezais, na safra do ano de 1933. Se desviou qualquer parte da produção empenhada, responderá civil e criminalmente pela ilicitude dos seus atos, cabendo ao credor os remedios possessorios contra terceiros que se hajam empossado dos cafés empenhados, pondo em exercicio o seu direito de sequela.

Isto posto, respondo:

Tendo o valor da divida, garantida com o penhor agricola, de que se trata, ficado reduzida de cincoenta por cento em seu valor, na data da publicação do decr. n. 23.533 , de 1 de dezembro de 1933; mas estando o prazo de um ano prorrogado por dez anos, pelo decr. n. 22.626, de 7 de abril de 1933 - o credor, se não fôr paga a primeira prestação anual, decorrido um ano da publicação dêste decreto, poderá, sem dúvida, como, de resto, ficou expresso no art. 10, paragr. unico, dêste, tambem chamado de "lei da usura", promover a competente ação de excução do penhor agricola, para o pagamento de todo o saldo em debito, juros, multa e despesas judiciais. (5)

(5) O ponto de rista lançado no texto foi modificado pelo decr. n. 23.981 .

Dispôs êle, com efeito, no art. 31:

"Se a divida estiver no regime da moratoria decenal concedida pelo art. 15 do decr. n. 22.626 , de 7 de abril de 1933, considerar-se-á a redução do presente decreto como pagamento antecipado das cinco primeiras prestações dessa moratoria, ficando o devedor obrigado apenas aos juros nas datas de tais prestações" 


\section{I}

Para verificar-se a importancia da dívida dos agricultores, na data da publicação do decr. n. 23.533, de 1 de dezembro de 1933, dever-se-á, naquela data, adicionar ao capital primitivo os juros até então vencidos. Apurada a soma de todas as parcelas, a divisão da sua importancia por dois fixa a da divida, pagavel em dez prestações anuais e iguais, continuadamente, nos termos do decr. n. 22.626, de 7 de abril de 1933, ainda não modificado por qualquer outro decreto posterior, neste particular.

São Paulo, 16 de janeiro de 1934 